\title{
Green polymer chemistry: lipase-catalyzed synthesis of bio-based reactive polyesters employing itaconic anhydride as a renewable monomer
}

\begin{abstract}
Syuhei Yamaguchi ${ }^{1}$, Matteus Tanha ${ }^{2,3}$, Anders Hult ${ }^{3}$, Tomoya Okuda ${ }^{1}$, Hitomi Ohara ${ }^{1}$ and Shiro Kobayashi ${ }^{4}$
Itaconic acid is a platform compound for bio-based renewable materials. This study employs itaconic anhydride (IAn) as a novel monomer for lipase-catalyzed ring-opening addition condensation polymerization (ROACP) involving dehydration to produce reactive polyesters. ROACP reactions were conducted by combining a cyclic anhydride and a diol. IAn, succinic anhydride (SAn) and glutaric anhydride (GAn) were used as the cyclic anhydrides, and 1,4-butanediol, 1,6-hexanediol, 1,8-octanediol and 1,10-decanediol were used as the diols. ROACP between two monomers, IAn and a diol, did not occur. Model reactions using IAn and $n$-octyl alcohol provided useful information about the regioselectivity and substrate selectivity of IAn. ROACP using three monomer components, IAn, SAn or GAn, and a diol, produced polyesters in good-to-high yields. From the SAn reactions, polyesters with $M_{\mathrm{n}}$ values of 650-3510 with 1.3-2.6 IAn units per molecule were obtained. From the GAn reactions, these values were 560-3690 and 1.2-3.1, respectively. The crosslinking reaction of a product polyester showed its reactive nature, giving a crosslinked hard solid polyester. The present polyesters derived from renewable starting materials have potential applications as macromonomers, telechelics, or crosslinking reagents, and the benign character of the ROACP reaction makes it appropriate for green polymer chemistry.

Polymer Journal (2014) 46, 2-13; doi:10.1038/pj.2013.62; published online 17 July 2013
\end{abstract}

Keywords: bio-based polymer; green polymer chemistry; itaconic anhydride; lipase; reactive polyester

\section{INTRODUCTION}

From the environmental perspective, particularly to reduce the amount of carbon dioxide emissions, it is highly desirable that polymeric materials be produced from bio-based, renewable

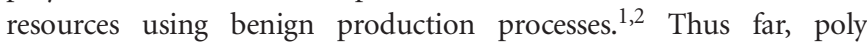
(lactic acid), which is produced using bio-based renewable resources, has been a leading example. ${ }^{3-13}$ Poly(lactic acid) has been prepared using two main methods, a ring-opening polymerization of lactide (a six-membered cyclic dimer of lactic acid) and direct polycondensation of lactic acid. Poly(lactic acid) is becoming widely used. ${ }^{3-13}$

To this end, we have performed the synthesis of bio-based polymeric materials from lactic acid-grafted polymers ${ }^{14-16}$ and have conducted 'green polymer chemistry' using enzyme catalysts. ${ }^{17-20}$

The lipase-catalyzed ring-opening polymerization of a dicarboxylic acid anhydrides, such as succinic anhydride (SAn), with a diol was first reported in 1993 for the ring-opening addition condensation polymerization (ROACP) involving dehydration. ${ }^{21}$ Lipase-catalyzed ring-opening copolymerization of compounds such as SAn with an oxirane monomer have also been performed. ${ }^{22-24}$ Regarding the dehydration, we proposed a new concept in organic chemistry, 'dehydration in water', using lipase-catalyzed polycondensation to produce polyesters in water. ${ }^{25,26}$ A similar dehydration condensation in water or in micelles was reported by another group. ${ }^{27,28}$ Enzymatic reactions in miniemulsions or micelle systems were also examined. ${ }^{29,30}$ We have recently described the enzyme-catalyzed synthesis of oligoesters from alkyl lactate monomers. ${ }^{31,32}$ As an extension of the above studies, the present paper reports the lipasecatalyzed synthesis of reactive polyesters employing itaconic anhydride (IAn), SAn or glutaric anhydride (GAn) as the starting monomer with four diols. The reaction produces various types of polyesters with a polymerizable vinylidene group derived from IAn. Our recent paper utilized IAn as a starting bio-based material to produce a poly(lactic acid) macromonomer. ${ }^{15}$ Itaconic and succinic acids and a $\mathrm{C}_{4}$ alcohol of 1,4-butanediol (BD) are regarded as renewable biomass materials; thus, IAn and SAn belong to the renewable biomass group as well. ${ }^{33}$ Lipase is a natural catalyst utilized in green chemistry. ${ }^{17-20,31,34-37}$ IAn is, to the best of our knowledge, a new substrate monomer for lipase-catalyzed polymerization.

${ }^{1}$ Department of Biobased Materials Science, Kyoto Institute of Technology, Kyoto, Japan; ${ }^{2}$ Royal Institute of Technology, Stockholm, Sweden; ${ }^{3}$ Department of Fiber and Polymer Technology, Royal Institute of Technology, Stockholm, Sweden and ${ }^{4}$ Center for Fiber and Textile Science, Kyoto Institute of Technology, Kyoto, Japan

Correspondence: Professor H Ohara, Department of Biobased Materials Science, Kyoto Institute of Technology, Kyoto, Japan or Professor S Kobayashi, Center for Fiber and Textile Science, Kyoto Institute of Technology, Kyoto 606-8585, Japan.

E-mail: ohara@kit.ac.jp or kobayash@kit.ac.jp

Received 5 April 2013; revised 20 May 2013; accepted 20 May 2013; published online 17 July 2013 


\section{EXPERIMENTAL PROCEDURE}

\section{Materials}

IAn was purchased from Sigma-Aldrich, St Louis, MO, USA. SAn and 1,6hexanediol (HD) were purchased from Nacalai Tesque (Kyoto, Japan). GAn and 1,10-decanediol (DD) were purchased from Tokyo Chemical Industry (Tokyo, Japan). 1,8-Octanediol (OD) was obtained from Wako Pure Chemical Industries (Tokyo, Japan). Immobilized lipase B (Novozym 435) was obtained from Novo Nordisk A/S (Bagsveerd, Denmark) and had a catalytic activity of $10000 \mathrm{PLUg}^{-1}$. The Novozym 435 sample was kept in a decompressed desiccator containing silica gel for 1 day and then kept in a screw bottle with silica gel in a refrigerator. Molecular sieves (3A), $n$-hexane, $n$-octanol $(\mathrm{OctOH})$, $\mathrm{BD}$ and deuterochloroform were purchased from Kanto Kagaku (Tokyo, Japan). Toluene, 1,4-dioxane and other solvents of extra-purity grade were commercial reagents from Nacalai Tesque and were used without further purification.

\section{Reaction of IAn with diol}

A mixture of IAn $(5.0 \mathrm{mmol})$, a diol $(5.0 \mathrm{mmol})$ and Novozym 435 (10 wt $\%$ for the total substrates) in $10 \mathrm{ml}$ of toluene was placed in a test tube and stirred at $25^{\circ} \mathrm{C}$ for $120 \mathrm{~h}$. When the diol was $\mathrm{BD}$ or $\mathrm{HD}$, the reaction mixture was concentrated in vacuo, resolved in chloroform and the Novozym 435 was removed by filtration. Then, the chloroform solution was poured into $n$-hexane to precipitate the polymeric products, which were further analyzed by ${ }^{1} \mathrm{H}$ nuclear magnetic resonance (NMR), gel permeation chromatography (GPC) and electrospray ionization time-of-flight mass spectrometry (ESI-TOF MS). When the diol was OD or DD, the reaction mixture was minimally soluble in chloroform; thus, the mixture was concentrated in vacuo. Then, the residual polymeric products were examined using ${ }^{1} \mathrm{H}$ NMR, GPC and ESI-TOF MS.

Table 1 Lipase-catalyzed ring-opening addition condensation polymerizations (ROACP) of IAn, SAn and diol to polyester

\begin{tabular}{|c|c|c|c|c|c|c|c|}
\hline \multirow[b]{5}{*}{ Code } & \multirow{5}{*}{$\begin{array}{c}\text { ROACP reaction }{ }^{\mathrm{a}} \\
\text { Feed monomer } \\
\text { (mmol) } \\
\text { IAn:SAn:diol }\end{array}$} & \multicolumn{6}{|c|}{ Product polyester } \\
\hline & & \multirow{4}{*}{$\begin{array}{l}\text { Yield } \\
(\%)^{b}\end{array}$} & \multirow{4}{*}{$\begin{array}{c}\text { Molar } \\
\text { unit (\%)c } \\
\text { An:SAn:diol }\end{array}$} & \multirow[b]{4}{*}{$\mathrm{M}_{n}^{\mathrm{d}}$} & \multirow[b]{4}{*}{$P D I^{d}$} & \multirow{4}{*}{$\begin{array}{l}\text { Numbers } \\
\text { of unit per } \\
\text { molecule } \\
\text { IAn/SAn/diol }\end{array}$} & \multirow{4}{*}{$\begin{array}{c}\text { Bio- } \\
\text { mass } \\
\text { content } \\
(w t \%)\end{array}$} \\
\hline & & & & & & & \\
\hline & & & & & & & \\
\hline & & & & & & & \\
\hline $1^{f}$ & $2.5: 2.5: 5.0(O D)$ & 0 & - & - & - & - & - \\
\hline $2^{f}$ & $2.5: 2.5: 5.0(O D)$ & 0 & - & - & - & - & - \\
\hline $3^{f}$ & $2.5: 2.5: 5.0(O D)$ & 90 & $25: 25: 50$ & 720 & 1.3 & $1.5 / 1.5 / 3.0$ & 40 \\
\hline 4 & $2.5: 2.5: 5.0(B D)$ & 0 & - & - & - & - & - \\
\hline 5 & 1.0:4.0:5.0 (BD) & 0 & - & - & - & - & - \\
\hline 6 & 2.5:2.5:5.0 (HD) & 87 & $21: 26: 53$ & 650 & 1.5 & $1.3 / 1.6 / 3.1$ & 42 \\
\hline 7 & 1.0:4.0:5.0 (HD) & 89 & $7: 41: 52$ & 2430 & 1.8 & $1.7 / 9.6 / 12.4$ & 42 \\
\hline 8 & 2.5:2.5:5.0 (OD) & 93 & $23: 26: 51$ & 1350 & 1.6 & $2.6 / 2.8 / 5.7$ & 39 \\
\hline 9 & 1.0:4.0:5.0 (OD) & 82 & $7: 39: 54$ & 2600 & 1.8 & $1.7 / 8.6 / 11.8$ & 34 \\
\hline $10^{g}$ & 2.5:2.5:5.0 (OD) & 92 & $21: 27: 52$ & 390 & 1.1 & $0.7 / 0.9 / 1.7$ & 38 \\
\hline $11^{\mathrm{g}}$ & 1.0:4.0:5.0 (OD) & 90 & $8: 41: 51$ & 490 & 1.2 & $0.3 / 1.7 / 2.2$ & 37 \\
\hline 12 & 2.5:2.5:5.0 (DD) & 81 & $23: 26: 51$ & 880 & 1.5 & $1.5 / 1.7 / 3.3$ & 35 \\
\hline 13 & 1.0:4.0:5.0 (DD) & 74 & $8: 38: 54$ & 3510 & 1.5 & $2.1 / 10.2 / 14.1$ & 31 \\
\hline \multicolumn{8}{|c|}{ 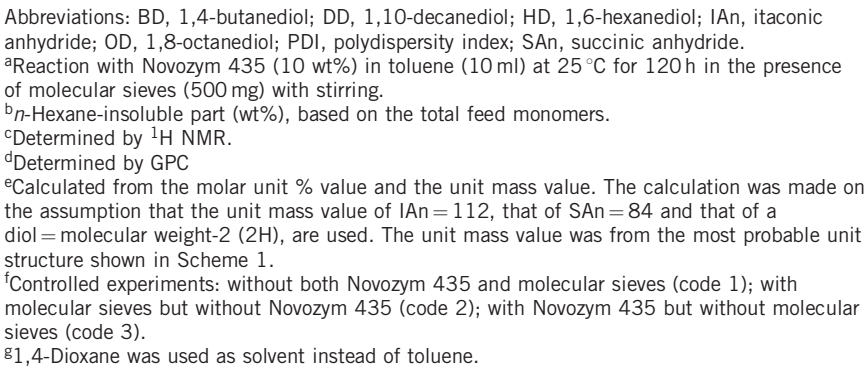 } \\
\hline
\end{tabular}

\section{Model reactions}

For the regioselectivity examination, a mixture of IAn $(1.0 \mathrm{mmol})$, OctOH $(1.0 \mathrm{mmol})$ and Novozym 435 (10 wt $\%$ for the total substrates) was placed in a test tube containing $2.0 \mathrm{ml}$ of toluene. The mixture was stirred at $25^{\circ} \mathrm{C}$ for $120 \mathrm{~h}$, during which a small portion $(0.05 \mathrm{ml})$ of the reaction mixture was taken out at specific time intervals for ${ }^{1} \mathrm{H}$ NMR analysis.

For the substrate selectivity examination, a typical procedure was as follows. A mixture of IAn $(1.0 \mathrm{mmol})$, SAn $(1.0 \mathrm{mmol})$, OctOH $(0.5 \mathrm{mmol})$ and Novozym $435(10 \mathrm{wt} \%)$ in 1,4-dioxane $(3 \mathrm{ml})$ was placed in a test tube. The mixture was stirred at $25^{\circ} \mathrm{C}$ for $24 \mathrm{~h}$, during which a small portion $(0.05 \mathrm{ml})$ of the reaction mixture was taken out at specific time intervals for the ${ }^{1} \mathrm{H}$ NMR spectroscopic analysis.

\section{Synthesis of polyester}

A typical run (code 12, Table 1) was as follows. A mixture of IAn ( $2.5 \mathrm{mmol})$, SAn $(2.5 \mathrm{mmol})$, DD $(5.0 \mathrm{mmol})$, Novozym 435 (10 wt $\%$ for the total monomers) and molecular sieves $3 \mathrm{~A}(500 \mathrm{mg})$ in toluene $(10 \mathrm{ml})$ in a $100-\mathrm{ml}$ reaction flask was stirred at $25^{\circ} \mathrm{C}$. After $120 \mathrm{~h}$, the reaction mixture was concentrated and chloroform was added to dissolve the mixture. Then, the chloroform solution was filtered to remove Novozym 435, and the solution was poured into a large volume of $n$-hexane to precipitate the products. The product polymer was separated by filtration and dried under vacuum to give the product, $1.09 \mathrm{~g}$, in $81 \%$ yield. Characterization of the product was performed by ${ }^{1} \mathrm{H}$ NMR and GPC analyses.

\section{Crosslinking reaction}

A polymer sample $(0.20 \mathrm{~g}$, code 5 , Table 2$)$ was heated without solvent in air at $150{ }^{\circ} \mathrm{C}$ for $27 \mathrm{~h}$ in a test tube. The sample was melted at the beginning. Gelation began after $\sim 3 \mathrm{~h}$, and the reaction mixture turned to soft solids and finally hard solids. For the extraction experiment, the crosslinked solid polymer $(40 \mathrm{mg})$ was dipped in chloroform $(1.0 \mathrm{ml})$ and stirred at room temperature for $2 \mathrm{~h}$. During the extraction, the solid became swollen. Then, the mixture was filtered and chloroform was evaporated to give the extracted polymer $(2.0 \mathrm{mg})$.

Table 2 Lipase-catalyzed ring-opening addition condensation polymerizations (ROACP) of IAn, GAn and diol to polyester

\begin{tabular}{|c|c|c|c|c|c|c|c|}
\hline \multirow[b]{5}{*}{ code } & \multirow[b]{2}{*}{ ROACP reaction ${ }^{a}$} & \multicolumn{6}{|c|}{ Product polyester } \\
\hline & & & & & & Num & Bio- \\
\hline & Feed monomer & & Molar unit & & & unit per & mass \\
\hline & (mmol) & Yield & $(\%)^{c}$ & & & molecule & content \\
\hline & IAn:GAn:diol & $(\%)^{\mathrm{b}}$ & IAn:GAn:diol & $\mathrm{M}_{n}^{\mathrm{d}}$ & $P D /^{\mathrm{d}}$ & IAn/GAn/diol & $(w t \%)$ \\
\hline 1 & 2.5:2.5:5.0 (BD) & 87 & $22: 26$ & 560 & 1.0 & 1.3 & 73 \\
\hline 2 & 1.0:4.0:5.0 (BD) & 68 & $7: 4$ & 1430 & 1.4 & 1.2 & 56 \\
\hline 3 & 2.5:2.5:5.0 (HD) & 79 & $22: 2$ & 710 & 1.4 & 1.4 & 22 \\
\hline 4 & 1.0:4.0:5.0 (HD) & 74 & $8: 4$ & 2420 & 1.6 & 11.4 & 8 \\
\hline 5 & 2.5:2.5:5.0 (OD) & 84 & $24: 26$ & 1610 & 1.5 & $3.1 /$ & 22 \\
\hline 6 & 1.0:4.0:5.0 (OD) & 73 & $8: 4$ & 3220 & 1.6 & 13.8 & 7 \\
\hline 7 & 2.5:2.5:5.0 (DD) & 84 & $23: 2$ & 1370 & 1.5 & $2.3 /$ & 19 \\
\hline 8 & 1.0:4.0:5.0 (DD) & 71 & $7: 41: 52$ & 3690 & 1.6 & 2.0/10.9/13.9 & 6 \\
\hline \multicolumn{8}{|c|}{ 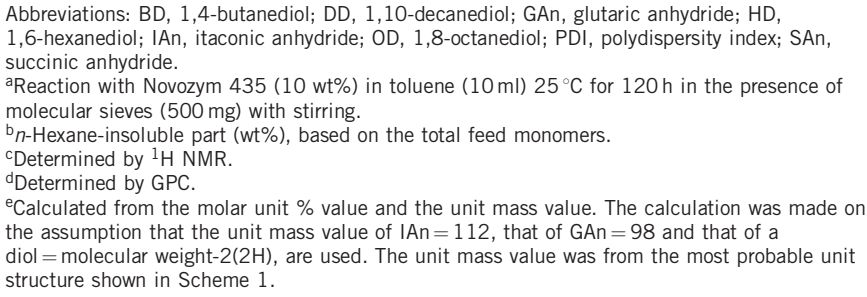 } \\
\hline
\end{tabular}




\section{Analytical methods}

${ }^{1} \mathrm{H}$ NMR measurements were recorded on an AV-300 spectrometer $(300 \mathrm{MHz}$, Bruker Biospin, Kanagawa, Japan). ESI-TOF MS analysis was performed using a microTOF instrument (ESI-TOF MS) (Bruker Daltonics, Bremen, Germany). The molecular weight of the polyesters was measured using a GPC instrument (GL-7400 Series, GL Science, Tokyo, Japan) with a refractive index detector using a chloroform eluent at a column temperature of $40^{\circ} \mathrm{C}$, in which the polystyrene standards (molecular weight $\left.=5.9 \times 10^{2}-6.5 \times 10^{5}\right)$ were employed. The Fourier transform infrared spectroscopy spectrum measurement was conducted on a PerkinElmer Spectrum GX instrument (PerkinElmer Japan, Yokohama, Japan) of the Spectra-tech Foundation series (Thermo Fisher Scientific K. K., Yokohama, Japan).

\section{RESULTS AND DISCUSSION}

\section{Reaction of IAn with diol}

Our previous paper described the lipase-catalyzed ROACP of a cyclic anhydride, such as SAn, with a diol, involving dehydration. ${ }^{21}$ IAn is a five-membered cyclic anhydride, that is, SAn substituted with a vinylidene group. Therefore, a similar ROACP reaction of IAn with four diols (BD, HD, OD and DD) with a feed molar ratio of IAn:diol $=1.0: 1.0$ with Novozym 435 catalyst in the presence of molecular sieves was examined at $25^{\circ} \mathrm{C}$ in toluene for $120 \mathrm{~h}$ (Scheme 1). All reactions remained inhomogeneous during the reaction and gave only low-molecular weight products with $M_{\mathrm{n}}$ between 150 and 390, as determined by GPC analysis. In reactions with the four diols, the starting IAn was completely consumed by the ring-opening reaction, which was confirmed through ${ }^{1} \mathrm{H}$ NMR of the reaction mixtures.

Furthermore, ESI-TOF MS analysis of the products was performed. As shown in the reactions of IAn with (I)-HD (H), I-OD (O) and I-DD (D), the reactions gave a mixture of products consisting $1: 1$ and 2:1 adducts of I:diol, as shown in Figures 1a-c, respectively. In all cases, the 2:1 adducts were the main products. Both $\mathrm{OH}$ groups of the diol reacted. The reaction mode of IAn was of the ring-opening addition (ROA) type, in which ROA via $\alpha$ - or $\beta$-addition occurred (see, Scheme 3 ). In the cases of $\mathrm{OD}$ and $\mathrm{DD}$, only a minimal amount of the 2:2 and 3:2 adducts were produced, as shown in Figures $1 \mathrm{~b}$ and c, respectively. This means that in addition to the main ROA reactions, condensation with dehydration occurred to a small extent. These results imply that the products consisted of those from the ROA; a 1:1 adduct having an alcohol-carboxylic acid terminal structure and a 2:1 adduct having a dicarboxylic acid terminal structure, whereas the subsequent dehydration of the 2:1 adduct resulting in elongation of the ester chain rarely occurred. These results imply that IAn alone does not induce the expected ROACP reaction under the reaction conditions. A likely cause is that IAn is less reactive than SAn in the ROACP involving a dehydration step. ${ }^{21}$ In relation to the above model reactions, the lipase-catalyzed ring-opening reaction of IAn with an alcohol was reported to produce a regioisomeric
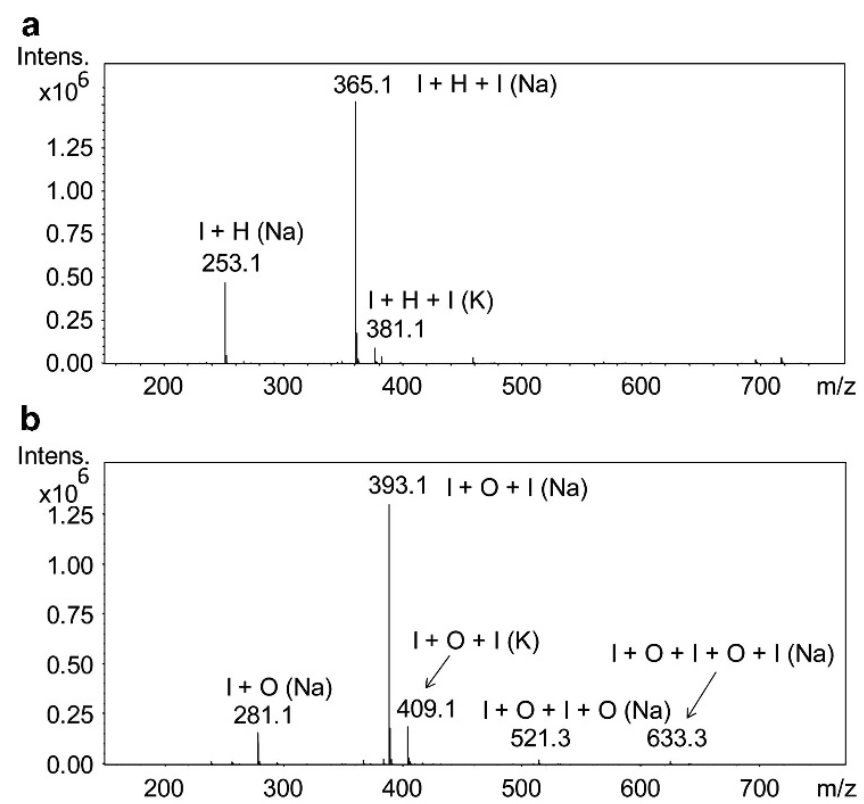

C

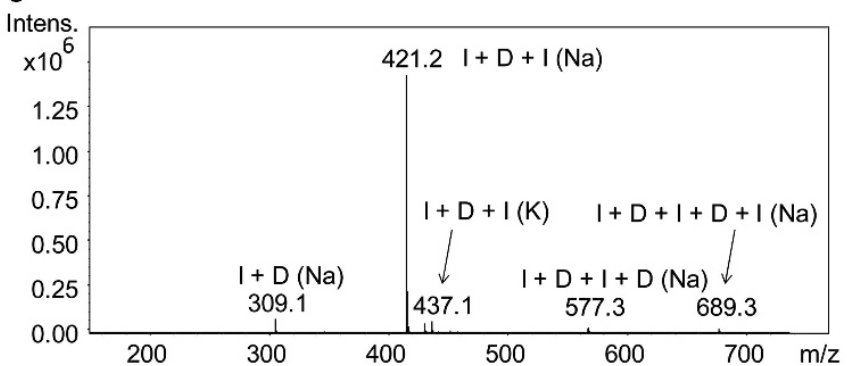

Figure 1 ESI-TOF MS charts: (a) products of the itaconic anhydride-1,6hexanediol (IAn-HD) reaction, (b) products of the IAn-1,8-octanediol (OD) reaction and (c) products of the $\mid A n-1,10-d e c a n e d i o l(D D)$ reaction. $(\mathrm{Na})$ and $(\mathrm{K})$ show the product complex of $\mathrm{Na}^{+}(m=23)$ and $\mathrm{K}^{+}(m=39)$, respectively.


Polyester

Scheme 1 Expected ring-opening addition condensation polymerization (ROACP) reaction using itaconic anhydride (IAn) and a diol. 
monoester, ${ }^{38}$ whereas the present results seemed more complicated because a diol was used.

\section{ROACP of IAn and SAn or GAn with a diol}

The above results suggested that for the production of polyesters with reactive vinylidene groups by a lipase catalyst, the combined use of IAn and SAn or GAn would be preferable for the reaction with a diol to induce ROACP involving dehydration. The main part of the present study is concerned with the results of these reactions. Some of the product polyesters are 'biomass plastics'; 'biomass plastics' indicates that the plastics contain a biomass content $>25 \mathrm{wt} \%$, according to the definition of the Japan BioPlastics Association proposed in 2006

The reaction mode of the present polymerization is shown in Scheme 2. In the reaction, Novozym 435 and molecular sieves were employed as the catalyst and dehydrating agent, respectively. The ROACP involves two different types of reaction: a ROA between a cyclic anhydride and a diol followed by a dehydration condensation between an alcohol group and a carboxylic acid group.
To obtain information about the product polyester structures and the fundamental aspects of IAn reactions, model reactions were conducted before the study of the ROACP reactions.

\section{Model reactions}

The first stage of ROACP is a ROA reaction between IAn or SAn (or GAn) and a diol, forming a product with hydroxyl and carboxylic acid terminal groups, which lead to the subsequent condensations. In contrast to SAn and GAn, IAn has an unsymmetrical anhydride structure with a vinylidene group substituent adjacent to a carbonyl group, thus providing two types of addition products $(\alpha-$ and $\beta$-adducts). This characteristic of the structure results in the regioselectivity between the two carbonyl groups of IAn toward nucleophilic attack of an alcohol, as shown in reaction (1; Scheme 3). To produce reactive polyesters containing at least one IAn unit in the polymer molecule, IAn has to be comparably in reactivity to SAn or GAn. This characteristic is related to the intermolecular reactivity, that is, substrate selectivity, between IAn and SAn (or GAn) toward an alcohol nucleophile, as shown in reaction (2; Scheme 3). To examine these points, model reactions were performed using $n$-octanol $(\mathrm{OctOH})$ instead of a diol.
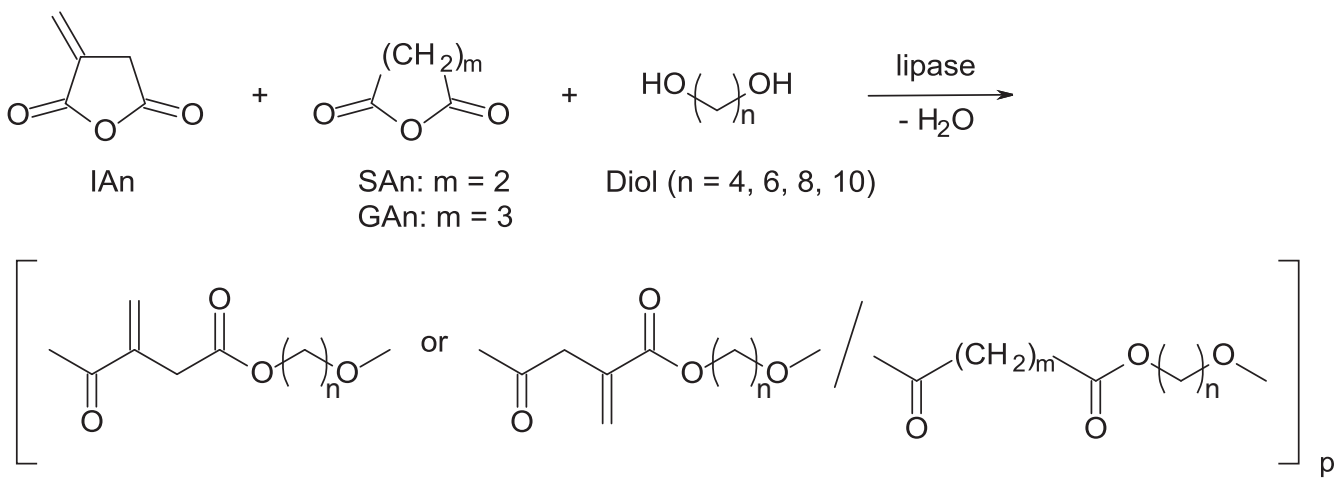

Reactive polyester

Scheme 2 Lipase-catalyzed ring-opening addition condensation polymerization (ROACP).

(1)
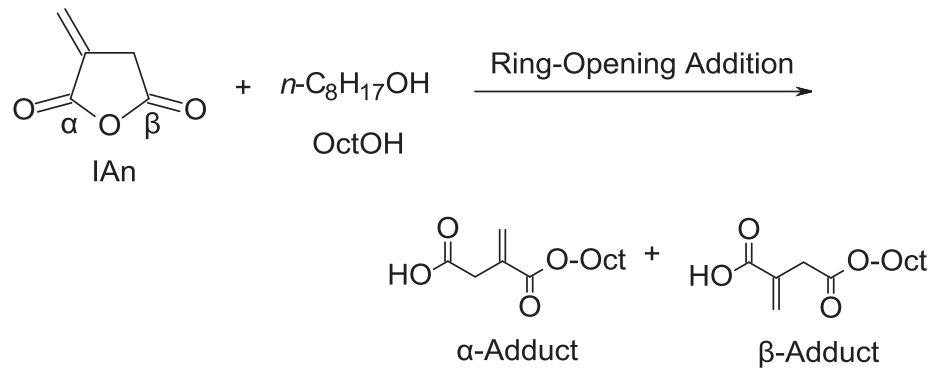

(2)
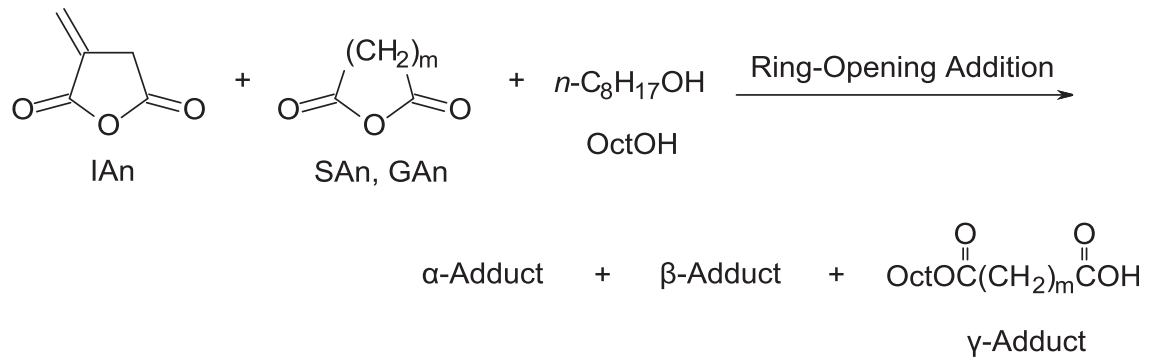

Scheme 3 Ring-opening addition (ROA) reactions between itaconic anhydride (IAn) and n-octanol (OctOH; reaction (1)) and between IAn, succinic anhydride (SAn) or glutaric anhydride (GAn) and $\mathrm{OctOH}$ (reaction (2)). 
Regioselectivity. An ROA reaction (1) was performed with Novozym 435 catalyst without molecular sieves in toluene at $25^{\circ} \mathrm{C}$ with stirring. The reaction was not perfectly homogeneous, but the regioselectivity can be studied because it is based on the intramolecular competition reaction. Figure $2 \mathrm{a}$ shows the ${ }^{1} \mathrm{H}$ NMR spectra of the reaction mixture. Spectrum is for a feed molar ratio of IAn:OctOH $=1.0: 1.0$. All peak assignments are provided along with the structures. In addition to triplet peak a $(\delta 6.48)$, from a vinylidene proton of the unreacted IAn, triplet-like peaks $\mathrm{a}^{\prime}$ and $\mathrm{b}^{\prime}$ at $\delta 6.43$ and 5.77 and triplet-like peaks $\mathrm{a}^{\prime \prime}$ and $\mathrm{b}^{\prime \prime}$ at $\delta 6.33$ and 5.69 are ascribed to the vinylidene protons of the $\beta$-adduct and $\alpha$-adduct, respectively. The selectivity for $\alpha$ and $\beta$ is almost equal; the ratio of $\alpha: \beta$ is $51: 49$. That is, the $\beta$-regioselectivity, calculated from $\beta /(\alpha+\beta) \times 100(\%)$, is $49 \%$. When the reaction was conducted with a feed molar ratio 1.0:3.0 for a longer reaction time, in addition to the four vinylidene proton peaks noted above, a new peak, $\mathrm{a}^{\prime \prime \prime}$, appeared at $\delta 6.31$ and was assigned to the vinylidene proton of the diester adduct, the structure of which is given in Figure 2b. The corresponding new vinylidene proton appeared as peak $\mathrm{b}^{\prime \prime \prime}$ at $\delta 5.65$. These peak assignments are supported by the results of a previous paper. ${ }^{15}$ The diester structure corresponds to the unit structure contained in the internal part of the product polyesters via ROACP.

Reaction (1) was performed in the presence and absence of Novozym 435 catalyst and was analyzed by ${ }^{1} \mathrm{H}$ NMR spectroscopy. The IAn conversion and $\beta$-selectivity curves are shown in Figures $3 \mathrm{a}$ and $\mathrm{b}$, respectively. The ROA reaction occurred without lipase but proceeded very slowly, reaching a 91\% conversion of IAn after 5 days. The lipase-catalyzed reaction proceeded rapidly; IAn was completely consumed within $12 \mathrm{~h}$. The $\beta$-selectivity without the lipase was $90 \%$ (Figure 3a), in contrast to $49 \%$ with the lipase catalyst (Figure 3b). This $\beta$-selectivity value with lipase catalysis (49\%) can be compared with the reported values of $87 \%$ with Sn-catalyst and $89 \%$ without catalyst in the IAn- $n$-butanol reaction. ${ }^{15}$ The present value (90\%) and reported values (87 and 89\%) are reasonable because the $\beta$-carbonyl group is sterically more favorable than the $\alpha$-carbonyl group adjacent to the vinylidene group. The present regioselectivity values, therefore, demonstrate that the reaction is governed by lipase catalysis.

These catalysis results help facilitate reactive polyester production by ROACP shown in Scheme 2. The catalysis results in IAn are being<smiles>[2H]C=C1CC(=O)OC1=O</smiles>

IAn<smiles>OCCCCCCCI</smiles>

$\mathrm{OctOH}$<smiles>CCCCCCCCOC(=O)/C=C(\I)C(=O)O</smiles>

$\beta$-Adduct<smiles>O=C(O)CC(C=CC[18F])C(=O)OCl</smiles>

$\alpha$-Adduct

$\mathrm{CHCl}_{3}$

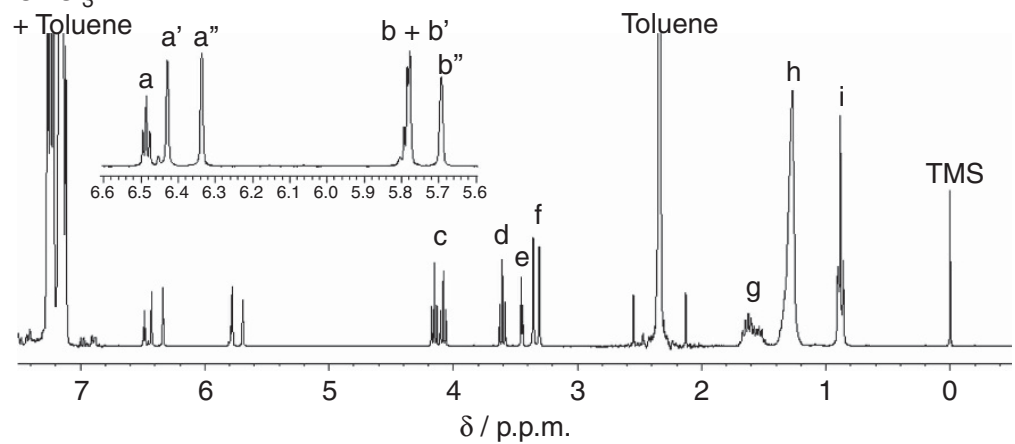

b

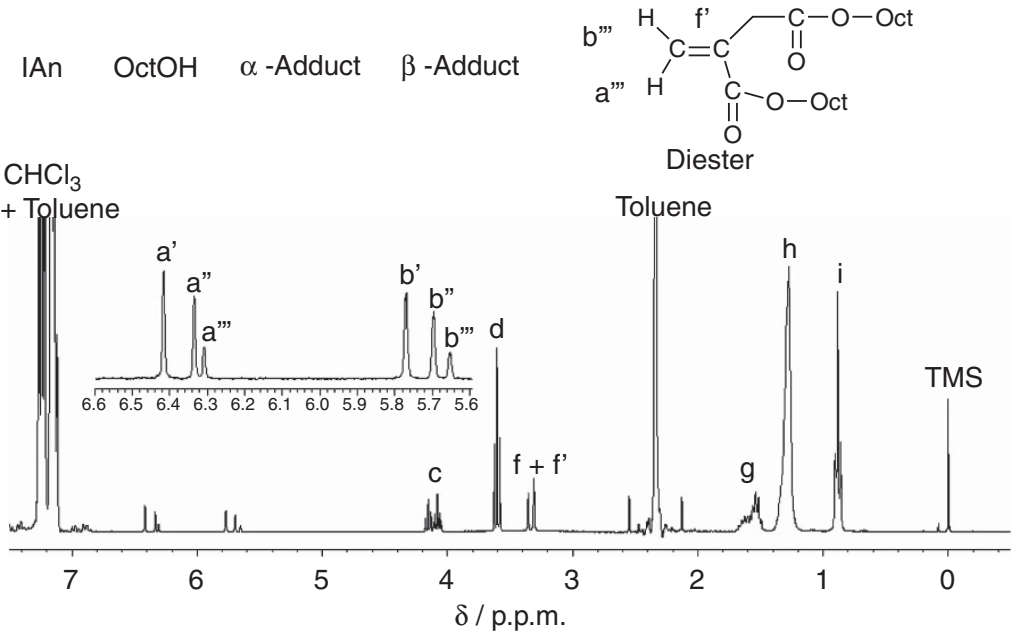

Figure $2{ }^{1} \mathrm{H}$ nuclear magnetic resonance (NMR) spectra $\left(\mathrm{CDCl}_{3}\right)$ of the reaction mixture of the Novozym 435-catalyzed reaction of itaconic anhydride (IAn) and $n$-octanol $(\mathrm{OctOH})$ in toluene at $25^{\circ} \mathrm{C}$, (a) with a 1.0:1.0 feed molar ratio for $6 \mathrm{~h}$ and (b) a 1.0:3.0 feed molar ratio for $72 \mathrm{~h}$. 
more easily incorporated into not only the terminal but also the internal portion of the polyester molecule, as discussed below.

The lipase-catalyzed model reaction (1) is explained in more detail by the mechanism shown in Scheme 4. As Novozym 435 belongs to the serine-lipase group, thus having a serine-methylol active site, it is represented as Lip-OH. First, the lipase attacks the $\alpha$-carbon of IAn to form an $\alpha$-acyl-enzyme intermediate (acylation step), and then $\mathrm{OctOH}$ attacks the activated carbonyl to give the $\alpha$-adduct and liberate Lip-OH (deacylation step). ${ }^{15,17-20,31}$ Likewise, the $\beta$-carbon of
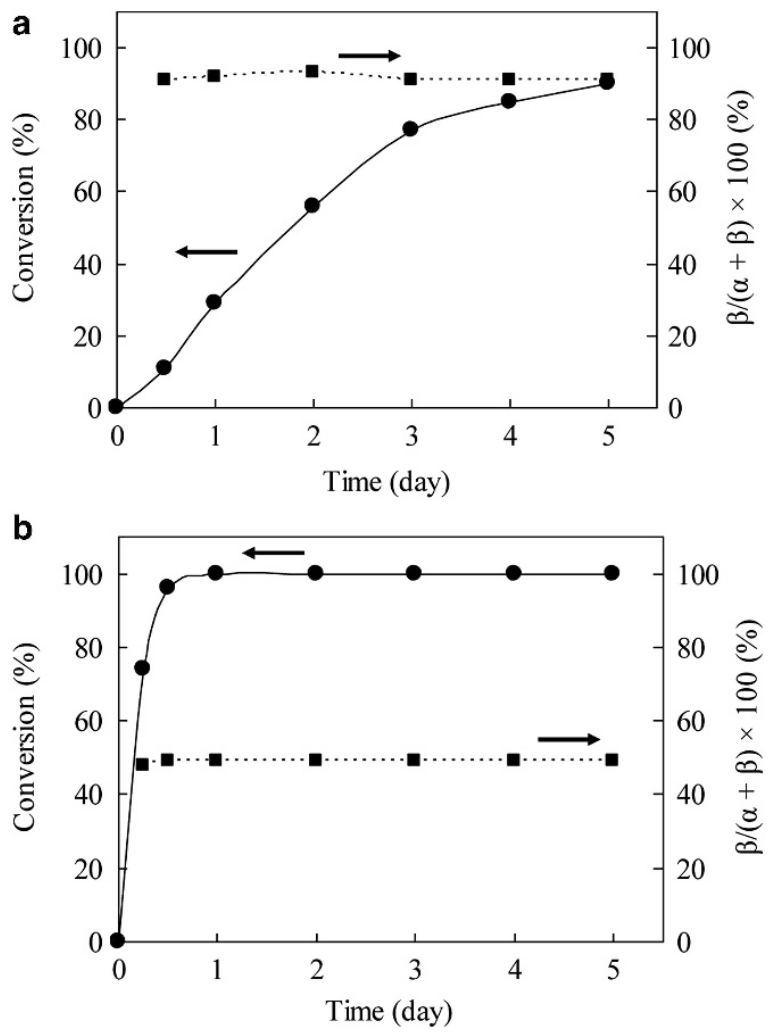

Figure 3 Time-IAn conversion and time $-\beta /(\alpha+\beta) \times 100$ (\%) curves: (a) reaction of itaconic anhydride (IAn) with $n$-octanol $(\mathrm{OctOH})$ without Novozym 435 and molecular sieves, and (b) reaction of IAn with OctOH in the presence of Novozym 435.
IAn is attacked by Lip-OH to give the $\beta$-acyl-enzyme intermediate (acylation step), and the intermediate produces the $\beta$-adduct through a deacylation step via attack from OctOH. In these steps, it is possible that the deacylation step is operative, based on our recent results. ${ }^{31}$

The $\alpha$ - and $\beta$-adducts are produced in almost equal quantities $(\alpha: \beta=51: 49)$, that is, although the $\alpha$-acyl-enzyme intermediate formation is considered less favorable than the $\beta$-acyl-enzyme formation owing to steric inhibition, the two adducts are produced in almost the same amount. Therefore, both $\alpha$ - and $\beta$-intermediate formation is accounted for by the above argument involving the production of polyesters having an IAn unit at the terminal region and/or in the internal region of the product polymer molecules.

Substrate selectivity. It is also important to know the relative reactivity of IAn and SAn or GAn in ROACP reactions in order to prepare reactive polyesters. The relative reactivity can be obtained by examining the substrate selectivity via a model reaction. The examination of the selectivity was conducted using an intermolecular competitive reaction; thus, the reaction is a homogeneous system. For this purpose, 1,4-dioxane was an appropriate solvent to provide a homogeneous reaction system from the beginning.

The competitive reaction ( $(2)$ in Scheme 3$)$ was conducted under the following conditions: IAn:SAn:OctOH $=1.0: 1.0: 0.5$ (all in mmol) with Novozym 435 (10 wt $\%)$ in $3.0 \mathrm{ml}$ of anhydrous 1,4-dioxane with stirring. When the ROA reaction was complete, the ${ }^{1} \mathrm{H}$ NMR spectrum of the reaction mixture (Figure 4a) showed two new peaks, $\mathrm{a}^{\prime \prime}$ and $\mathrm{a}^{\prime \prime \prime}$, at $\delta 6.36$ and 6.33 , respectively, due to the two types of vinylidene protons of the IAn-OctOH product as well as a new triplet-like peak, g, at $\delta 2.62$ from the ethylene protons of the SAn$\mathrm{OctOH}$ product and originating from the SAn proton peak $\mathrm{f}$ at $\delta 2.98$. Peak $\mathrm{a}^{\prime}(\delta$ 6.38) is from the hydrolysis product of IAn and not the product with OctOH. Thus, the consumption of IAn and SAn can be followed by ${ }^{1} \mathrm{H}$ NMR spectroscopy from the integrated values of the peaks. After $3 \mathrm{~h}$, the IAn and SAn were 13 and $27 \%$ consumed, respectively. This means that the ROA reactivity ratio of IAn:SAn toward OctOH is 0.48. Peaks $\mathrm{b}, \mathrm{b}^{\prime}, \mathrm{b}^{\prime \prime}$ and $\mathrm{b}^{\prime \prime \prime}$ due to another vinylidene proton are similarly assigned, as indicated in the figure. Without the lipase catalyst, the corresponding reaction did not occur to an appreciable extent.

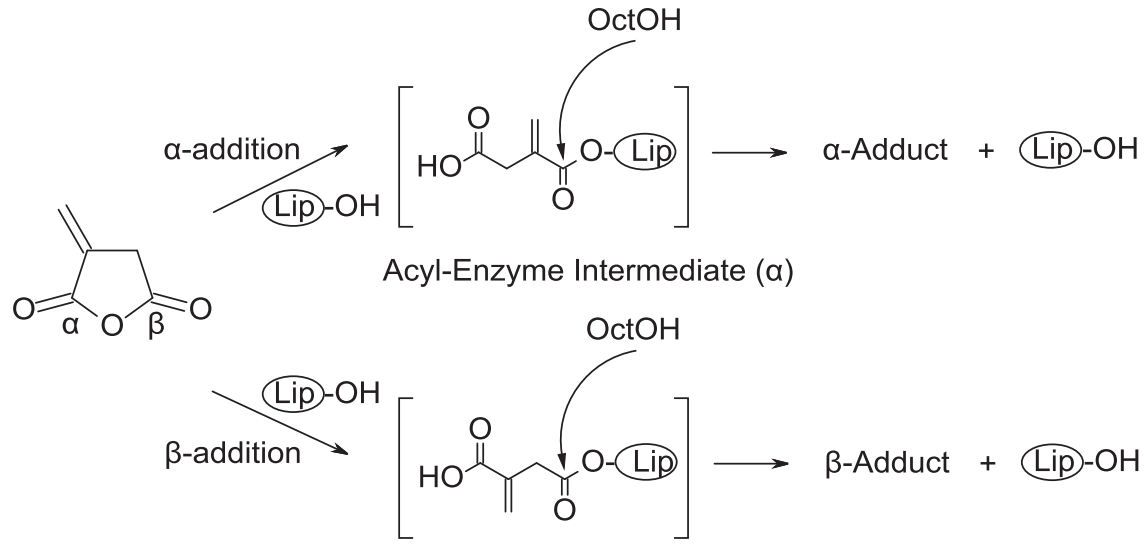

Acyl-Enzyme Intermediate $(\beta)$

Scheme 4 Postulated mechanism of the ring-opening addition (ROA) of n-octanol (OctOH) to itaconic anhydride (IAn) through an acyl-enzyme intermediate with lipase catalysis to form the $\alpha$ - and $\beta$-adducts. 
a<smiles>[2H]C=C1CC(=O)OC1=O</smiles>

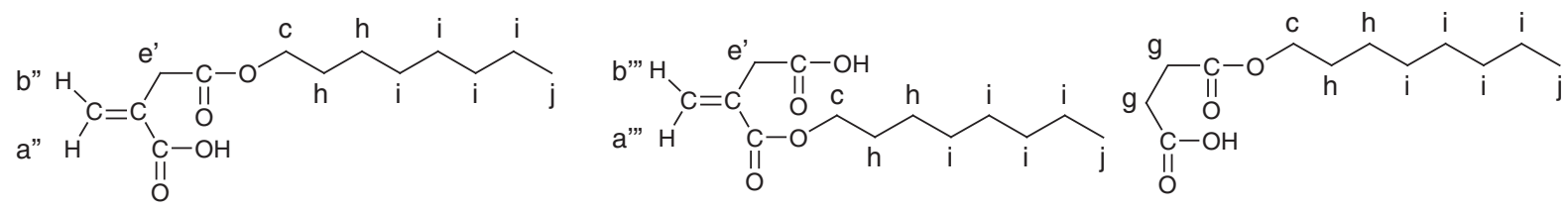

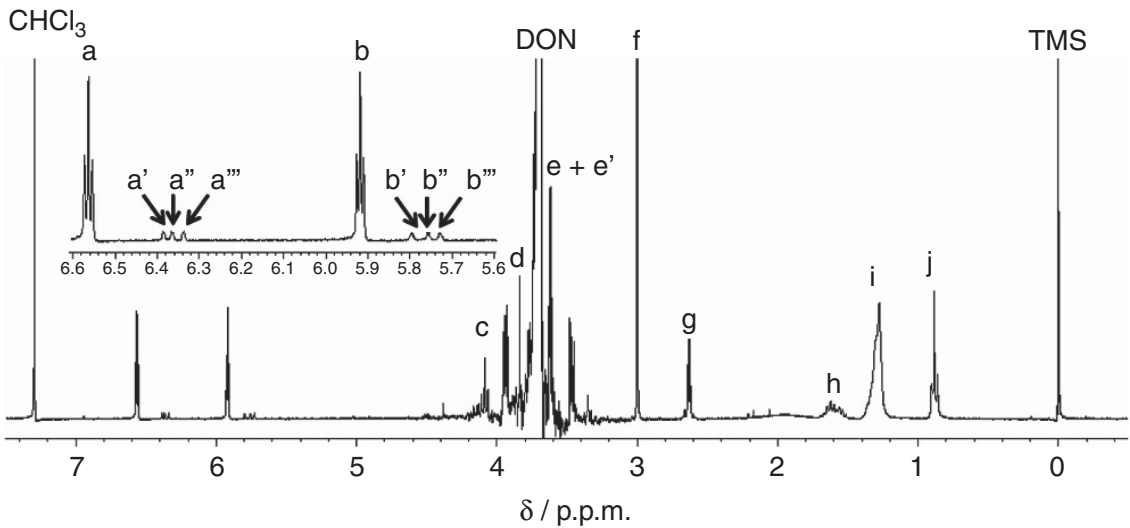

b<smiles>[2H]C=C1CC(=O)OC1=O</smiles><smiles>[10BH]C=C([CH]C(=O)O)C(=O)O</smiles><smiles>O=C1[CH][CH][I-]C(=O)O1</smiles><smiles>CC(C)C(C)CCCO</smiles>



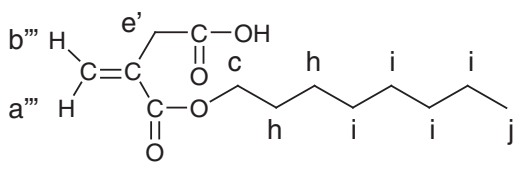<smiles>[X]C(=O)CC([X])C(=O)OCCCC(I)C(I)C(I)C(I)I</smiles>



Figure $4{ }^{1} \mathrm{H}$ nuclear magnetic resonance (NMR) spectra $\left(\mathrm{CDCl}_{3}\right)$ of the Novozym 435 -catalyzed competitive reaction in 1,4 -dioxane at $25^{\circ} \mathrm{C}$ for $3 \mathrm{~h}$ : (a) reaction mixture of itaconic anhydride $(\mathrm{IAn})$ :succinic anhydride $(\mathrm{SAn}): n$-octanol $(\mathrm{OctOH})=1.0: 1.0: 0.5(\mathrm{mmol}$ each) in the feed and (b) reaction mixture of IAn:glutaric anhydride (GAn): $\mathrm{OctOH}=1.0: 1 \cdot 0: 0.5$ (mmol each) in the feed.

GAn was employed for the competitive reaction in a manner similar to the SAn case. The consumption of IAn and GAn was determined by ${ }^{1} \mathrm{H}$ NMR spectroscopy using the integration values of peaks $\mathrm{a}^{\prime \prime}, \mathrm{a}^{\prime \prime \prime}$ and $\mathrm{k}$ (Figure $4 \mathrm{~b}$ ). After $3 \mathrm{~h}$, the consumptions of
IAn and GAn were 14 and 26\%, respectively. This means that the ROA reactivity ratio of IAn:GAn toward OctOH is 0.54 . Again, peak $\mathrm{a}^{\prime}$, from the hydrolysis product of Ian, was excluded from the calculation. 
The substrate selectivity values were obtained in 1,4-dioxane, in contrast to the polymerization solvent toluene. However, it provides significant reference data in that IAn is $\sim 0.5$ times as reactive as SAn and GAn in the ROA with the OctOH nucleophile. This implies that IAn is readily incorporated into the polyester products, in this case at the polymer terminal, to provide a reactive vinylidene group through the lipase-catalyzed ROACP reaction (vide infra).

\section{ROACP reactions using IAn, SAn and diol}

The ROACP reaction was performed under varying reaction conditions. The results of the ROACP reactions employing IAn and SAn with the four diols are shown in Table 1. Taking the substrate selectivity value of IAn/SAn in the model reaction into account, the feed molar ratios of IAn:San (or GAn): diol = 2.5:2.5:5.0 and 1.0:4.0:5.0, respectively, were used to produce the reactive polyesters.

Controlled reactions were conducted to examine the function of Novozym 435 and the molecular sieves in the ROACP reactions using an IAn:SAn:OD feed ratio of 2.5:2.5:5.0 in toluene at $25^{\circ} \mathrm{C}$ with stirring. These reactions gave inhomogeneous coagulated mixtures from the beginning, and the reaction mixture remained nearly unchanged even after $120 \mathrm{~h}$. Without Novozym 435, no product insoluble in $n$-hexane was produced (codes 1 and 2). With the lipase but without molecular sieves, the reaction system gradually became homogeneous (excluding the Novozym 435 powder) to produce polymeric products with an $M_{\mathrm{n}}$ value of 720 (code 3). When the molecular sieves were present, the ROACP was accelerated and gave polyesters with higher $M_{\mathrm{n}}$ values (code 8).

As the use of molecular sieves was preferred, all of the following ROACP reactions employed molecular sieves. The ROACP reactions of IAn-SAn-diol in the presence of Novozym 435 and molecular sieves in toluene at $25^{\circ} \mathrm{C}$ with stirring were inhomogeneous at the beginning and gradually became homogeneous with the progress of the reaction. After $120 \mathrm{~h}$, the reaction produced polyesters with polymerizable vinylidene groups and $M_{\mathrm{n}}$ values up to 3510 in high yields (Table 1). The reaction of IAn, SAn and BD, however, was an exception. In this reaction the ROA reaction was found to occur partially, whereas the polymerization did occur, as determined by examining the reaction mixture with ${ }^{1} \mathrm{H}$ NMR spectroscopy. The reaction system did not become homogeneous during the reaction (codes 4 and 5 in Table 1). The BD reaction systems were likely not hydrophobic enough for lipase catalysis in toluene.

Reactions using HD gave polyesters of $M_{\mathrm{n}} 650$ and 2430 for the feeds of IAn:SAn:HD = 2.5:2.5:5.0 and 1.0:4.0:5.0 (mmol each), respectively, in 87 and $89 \%$ yields (codes 6 and 7).

When OD was used, the reaction with IAn:SAn:OD $=2.5: 2.5: 5.0$ (mmol each) produced polyesters having an $M_{\mathrm{n}}$ of 1350 in $93 \%$ yield in toluene (code 8 ). A typical ${ }^{1} \mathrm{H}$ NMR spectrum of the product polyester is shown in Figure 5 in which the polyester structure is also given. All of the spectrum peaks are assigned except for the triplet-like peak c centered at $\delta 3.63$, which is attributed to the methylene protons of the terminal group $-\mathrm{CH}_{2} \mathrm{OH}$. There are peaks representing the respective structural units of IAn, SAn and OD, that is, peak a (multiple peaks at $\delta 6.31-6.48$ and 5.69-5.85) is due to the vinylidene protons $(2 \mathrm{H})$ of IAn, peak e (centered at $\delta 2.62)$ is due to the ethylene protons $(4 \mathrm{H})$ of SAn and peak $\mathrm{g}$ (centered at $\delta 1.33$ ) is due to the four methylene protons $(8 \mathrm{H})$ of OD. From the peak integration values, the molar unit (\%) value was determined to be IAn:SAn:OD = 23:26:51.

When the unit mass values were assumed to be the most probable value in the polymer chain, $\mathrm{IAn}=112, \mathrm{SAn}=84$ and $\mathrm{OD}=144$ $\left(\mathrm{C}_{8} \mathrm{H}_{18} \mathrm{O}_{2}-2 \mathrm{H}\right)$, the numbers of the respective units contained per molecule were calculated from the $M_{\mathrm{n}}$ value and the molar unit \% value, and were found to be IAn/SAn/OD $=2.6 / 2.8 / 5.7$. This implies that, on average, 2.6 reactive double bond groups are present at the terminal and/or the internal regions of the product molecule. If the molecule contains one double bond, it can be regarded as a polyester macromonomer, similar to a previously reported example. ${ }^{15}$ If the polyester has more than two double bonds, it can be thought of as a telechelic polyester or crosslinking agent. Thus, a reactive double bond group present at a rate of at least one per molecule is preferable.

In the reaction of a feed molar ratio of IAn:SAn:OD = 1.0:4.0:5.0 (mmol each; code 9), the product polyester showed a higher $M_{n}$ of 2600 with a lower quantity of IAn units incorporated into the polymer, indicated by the unit number ratio of IAn:SAn:OD $=1.7: 8.6: 11.8$. The higher-molecular weight value is most likely caused by the higher condensation polymerizability of SAn compared with IAn.
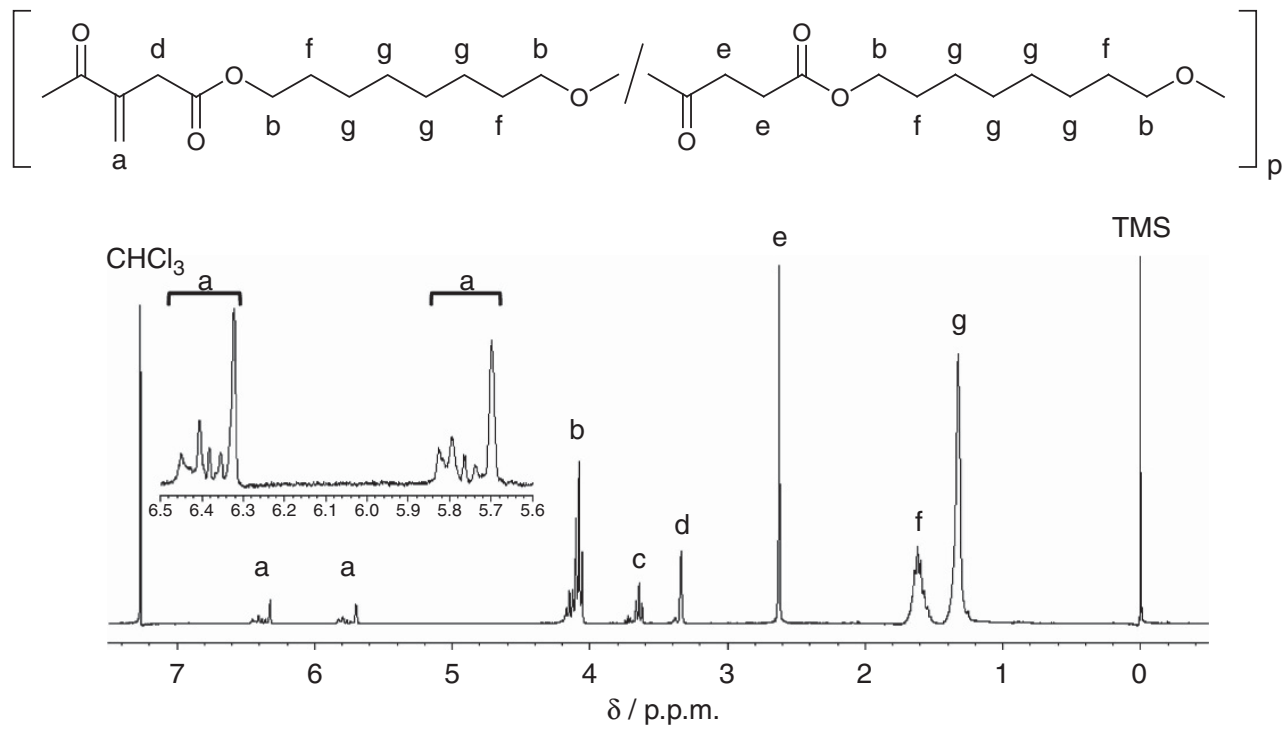

Figure $5{ }^{1} \mathrm{H}$ nuclear magnetic resonance (NMR) spectrum $\left(\mathrm{CDCl}_{3}\right)$ of the reaction product of itaconic anhydride (IAn):succinic anhydride (SAn):1,8octanediol $(O D)=2.5: 2.5: 5.0($ mmol each) in toluene (code 8$)$. 
The values of the average number of monomer units per molecule for the other ROACP reactions were similarly obtained using a combination of the ${ }^{1} \mathrm{H}$ NMR spectra and $M_{\mathrm{n}}$ values of the products, as shown in Table 1 .

1,4-Dioxane was not preferred over toluene as the solvent. The ROACP of the IAn-SAn-OD combination produced low-molecular weight products containing a lesser amount of the reactive double bond $(<1.0)$ at two feed molar ratios (codes 10 and 11).

The ROACP of IAn-SAn-DD also occurred. The product polyesters were obtained in high yield. Two polyesters showed $M_{\mathrm{n}}$ values of 880 and 3510 and possessed 1.5 and 2.1 double bonds per molecule, respectively, (codes 12 and 13 ).

A hypothesis was proposed from the ${ }^{1} \mathrm{H}$ NMR spectroscopic results of the model reactions above. A vinylidene proton peak due to the IAn-OctOH (1:2) adduct (diester) appears as a singlet-like peak at $\delta$ 6.31, as shown in Figure 2. Therefore, if the singlet-like peak centered at $\delta 6.32$ (Figure 5) results from a vinylidene proton of the IAn unit of the diester type, the content of the IAn unit internally present in the polyester molecule can be estimated from the total integrated value of the peaks $(\delta 6.31-6.48)$ as $49 \%$. Accordingly, the content of the IAn unit located at the terminal of the molecule is $51 \%$. The vinylidene protons at the terminal appear as multiple peaks, most likely because of the effects due to steric reasons, molecular weight factors and so on. When this calculation was performed from the peaks at $\delta 5.69-5.85$ with the assumption that the singlet-like peak at $\delta 5.70$ (Figure 5 ) is due to the diester adduct ( $\delta 5.65$, Figure 2 ), the IAn units were present at $50 \%$ both in the internal region and at the terminal. Thus, both values obtained from the calculation using two types of vinylidene protons were almost identical, suggesting that the above hypothesis was reasonable.

Similar to the above OD case, the IAn-SAn-HD reaction (2.5:2.5:5.0 feed ratio, code 6) showed a singlet-like peak centered at $\delta 6.32$ among peaks ( $\delta 6.31-6.45)$ attributed to the vinylidene. The $6.4 \%$ integrated value is considered to be the internally located IAn double bond (see Supplementary Figure S1). From the peaks at $\delta 5.63-5.84$, the peak at $\delta 5.64$ corresponds to $7.2 \%$ of the internal IAn double bond; both of the calculated values, 6.4 and $7.2 \%$, are comparable. The IAn-SAn-DD reaction (2.5:2.5:5.0 feed ratio, code 12) involved the singlet at $\delta 6.32$ (among peaks at $\delta 6.31-6.48$ ) of the vinylidene and contained $26 \%$ of the internal IAn double bond (see Supplementary Figure S2). Among the other peaks at $\delta 5.65-5.85$, the peak at $\delta 5.69$ occupied 29\%, again comparable to the value of $26 \%$. In the case of the IAn-SAn-BD reaction, however, no corresponding peaks at $\delta \sim 6.3$ and $\delta \sim 5.6$ were observed, suggesting that internal IAn double bonds are not present (see Supplementary Figure S3). These data help to elucidate the structures of the reactive polyesters.

As the ROACP is a three monomer component reaction, the entire structure of the product polymer is very complicated, and the structure shown in Scheme 2 does not represent it in adequate detail. Therefore, by combining all of the obtained data, a more detailed structure of the code 8 polyester was attempted. The polyester sample is produced from the unit content ratio IAn:San:OD $=2.6: 2.8: 5.7$. Scheme 5 shows a proposed structure in which the polymer terminal group structures are provided. The above analysis gave $\sim 50 \%$ for both the internal and terminal unit contents of IAn; thus, the terminal unit content of the $-\mathrm{CO}_{2} \mathrm{H}$ group from IAn corresponds to 1.3 $(=2.6 \times 0.5)$. The other terminal unit content of the $-\mathrm{CH}_{2} \mathrm{OH}$ group must then be 0.7 . This value was also supported by the calculated integration value of peak c, in Figure 5, as 0.72. Therefore, the internal unit content of (SAn-OD) is 2.1. Thus, the content of the carboxylic acid terminal group of SAn is very small, if any at all is present, because the carboxylic acid group from IAn is much more unreactive in the dehydration condensation than that from SAn, as observed in Figure 1. Therefore, the SAn content at the terminal was not taken into account. From the proposed structure, the total unit contents of OD are 5.4, which is different from 5.7. This difference, however, may be due to the unit mass value assumption and the experimental and/ or analytical accuracy.

These structural examination results of the other polyesters obtained from the reactions given in Supplementary Figures S1 and S2 are also shown in Supplementary Table S1.

Of the four diols used, OD was the most desirable diol in terms of yield, molecular weight and numbers of unit per molecule, as observed previously. ${ }^{21}$ This may be because the hydrophobicity of the reaction system of $\mathrm{OD}$ in toluene is appropriate for lipase catalysis.

The biomass contents of all of the product polyesters are within 31-42 wt $\%$ ( $>25 \mathrm{wt} \%$ ). Therefore, they can be considered 'biomass plastics'.

Thus, the ROACP reaction occurred under mild conditions (reaction temperature of $25^{\circ} \mathrm{C}$ ) with a green catalyst (lipase enzyme), and the reaction was benign.

\section{ROACP reactions using IAn, GAn and diol}

The six-membered cyclic acid anhydride GAn was used in place of SAn. Similar to the SAn reactions, feed molar ratios of IAn:GAn:diol =2.5:2.5:5.0 and 1.0:4.0:5.0 were employed for the reaction (Table 2). First, the explanation of the ${ }^{1} \mathrm{H}$ NMR spectrum of the reaction product from the ROACP of IAn:GAn:DD (2.5:2.5:5.0; code 7) will be discussed. In addition to the powdery catalyst, the reaction proceeded homogeneously and produced polyesters in $84 \%$ yield after precipitation from $n$-hexane. The products are powdery to sticky materials with an $M_{\mathrm{n}}$ value of 1370 . The products are powders when the $M_{\mathrm{n}}$ value is higher than $\sim 3000$ and are sticky to viscous materials when the $M_{\mathrm{n}}$ value is in the several hundreds. The ${ }^{1} \mathrm{H}$ NMR spectrum of the products is shown in Figure 6, together with the peak assignments. The triplet-like peak c centered at $\delta 3.63$ is assigned to the methylene protons of the terminal- $\mathrm{CH}_{2} \mathrm{OH}$ group. Peaks representing the respective structural units of IAn, GAn and DD are as follows. Peak a (multiple peaks at $\delta 6.31-6.48$ and 5.66-5.86) is due to the vinylidene protons $(2 \mathrm{H})$ of IAn, a multiplet peak $\mathrm{f}$ (centered at $\delta$ 1.95) is due to the methylene protons $(2 \mathrm{H})$ of GAn and peak $\mathrm{h}$

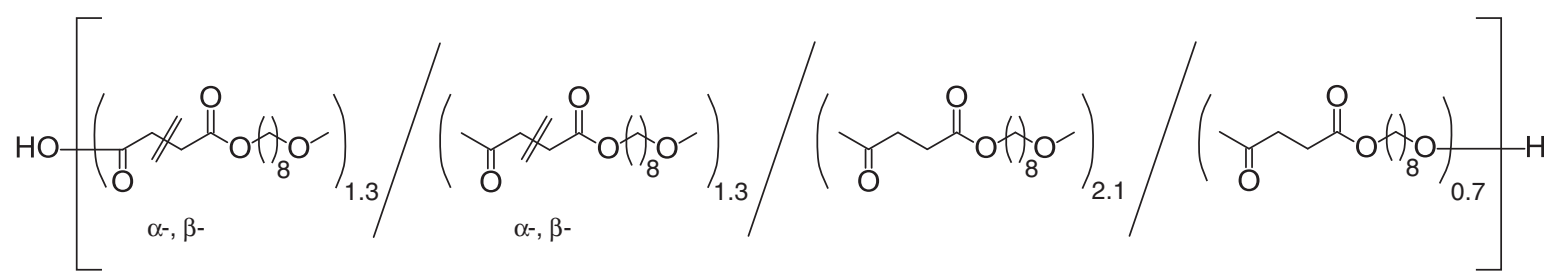

Scheme 5 Proposed structure for the polyester produced from itaconic anhydride (IAn), succinic anhydride (SAn) and 1,8-octanediol (OD); (code 8). 
(centered at $\delta 1.30)$ is due to the six methylene protons $(12 \mathrm{H})$ of DD. These peak integration values gave molar unit (\%) values of IAn:GAn:DD $=23: 26: 51$. From these values, as well as the $M_{\mathrm{n}}$ value of the polymer, the number of the respective units contained per molecule was $\mathrm{IAn} / \mathrm{GAn} / \mathrm{DD}=2.3 / 2.5 / 5.1$. This means that 2.3 reactive double bond groups on an average are present at the terminal and/or in the internal region of the molecule.

In contrast to the reaction with SAn, the ROACP of $\mathrm{BD}$ gave product polyesters in good-to-high yields for the two feed molar ratios (codes 1 and 2). The products have $M_{\mathrm{n}}$ values of 560 and 1430, with 1.3 and 1.2 double bonds per molecule, respectively. HD, OD and DD were also suitable monomers for the ROACP with the Novozym 435 catalyst in toluene (codes $3-6$ and 8 in Table 2). The molecular weights of the products ranged from 560 to 3690 . The product polyesters contained 1.2-3.1 reactive double bond groups per molecule.

Again, a similar hypothesis was proposed based on the spectrum (Figure 6); the singlet-like peak at $\delta 6.32$ is due to the internal double bond and $36 \%$ of the total double bonds were present internally, as shown by the integration value of that peak compared with the total integration value of the peaks at $\delta 6.31-6.48$. Thus, $64 \%$ of the double bonds are at the terminal of the molecule. A similar calculation was made based on the peaks at $\delta 5.67-5.86$, which resulted in an internal double bond ratio of $37 \%$, assuming that the singlet-like peak at $\delta$ 5.69 is due to the diester-type IAn unit structure. The values of 36 and $37 \%$ are very close, showing that the hypothesis is not unreasonable. Similarly, from the expanded ${ }^{1} \mathrm{H}$ NMR spectra, the content of the double bonds located in the internal region of the polyester molecules was calculated. Among the multiple peaks at $\delta \sim 6.3-\sim 6.5$ from the vinylidene proton, a singlet-like peak centered at $\delta \sim 6.3$ was attributed to the diester structure of IAn, that is, the internal double bond in the polyesters. The contents were 11\% for BD (code 1; see Supplementary Figure S4), $8.0 \%$ for HD (code 3; see Supplementary Figure S5) and $51 \%$ for OD (code 5; see Supplementary Figure S6).

Similar to Scheme 5, a more detailed structure for the polyester of code 7 was attempted. The polymer sample showed a unit content ratio of IAn:GAn:DD = 2.3:2.5:5.1. A proposed polyester structure is given in Scheme 6. The internal and terminal IAn contents were 37 and $63 \%$, respectively; hence, the unit contents were 0.9 and 1.4, respectively. These values indicate that the terminal $-\mathrm{CH}_{2} \mathrm{OH}$ unit content is 0.6, and that for the internal (GAn-DD) unit is 1.9. Again, the unit content of the terminal carboxylic acid from GAn was not accounted for. The unit content of the alcohol terminal structure was calculated from the integration value, 0.76 , of peak $c$ due to the $-\mathrm{CH}_{2} \mathrm{OH}$ in Figure 6. The values of 0.6 and 0.76 do not agree well, and the total number of IAn and GAn units is 4.8, different from the total number of DD units, 5.1; however, these differences may be due to the unit mass value assumption as well as experimental and/or analytical accuracy. For reference, further attempts were made to predict the structures of the other polyester samples by using the information from Supplementary Figures S4-6. The results are shown in Supplementary Table S1.

In general, the feed molar ratio of IAn:SAn (or GAn):diol= 1.0:4.0:5.0 gave polyesters with a relatively higher molecular weight but with a lower amount of incorporated IAn, as shown in Tables 1 and 2. Such polyesters are less desirable as 'reactive polyesters' because of the reduced number of vinylidene double bonds. Therefore, the structures of polyesters obtained from this feed molar ratio were not examined in detail compared with those from the ratio 2.5:2.5:5.0.

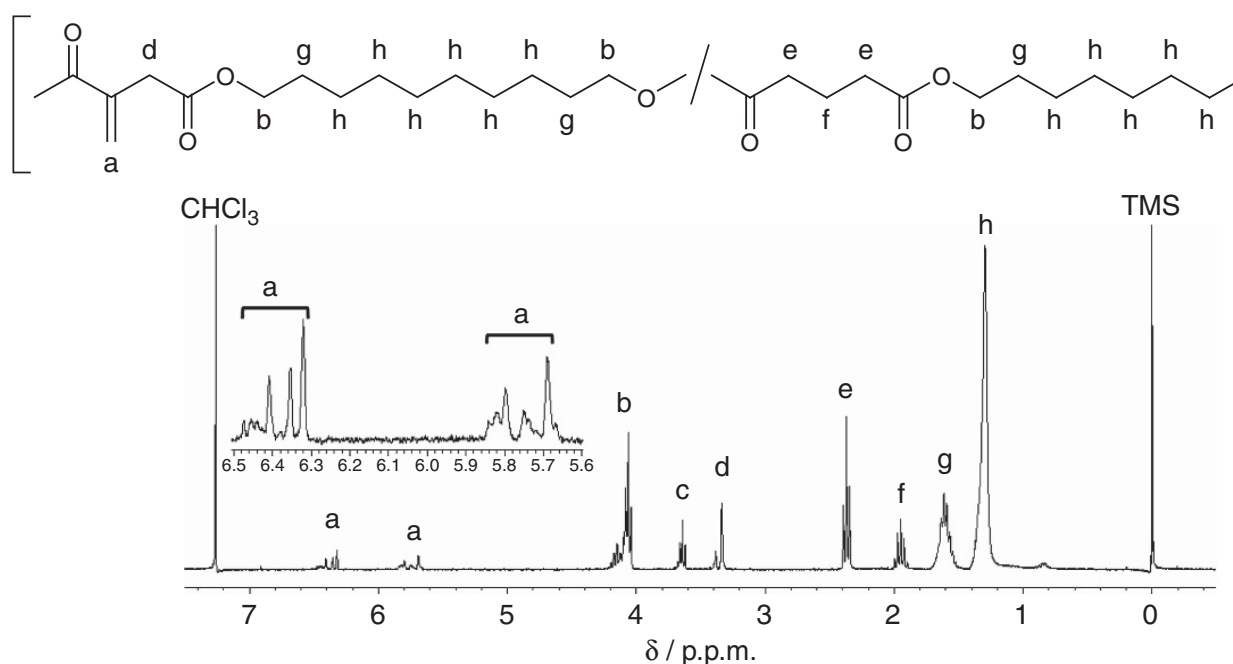

Figure $6{ }^{1} \mathrm{H}$ nuclear magnetic resonance (NMR) spectrum $\left(\mathrm{CDCl}_{3}\right)$ of the products from the ROACP reaction with the feed ratio itaconic anhydride (IAn):glutaric anhydride (GAn):1,10-decanediol (DD) = 2.5:2.5:5.0 (mmol each; code 7).

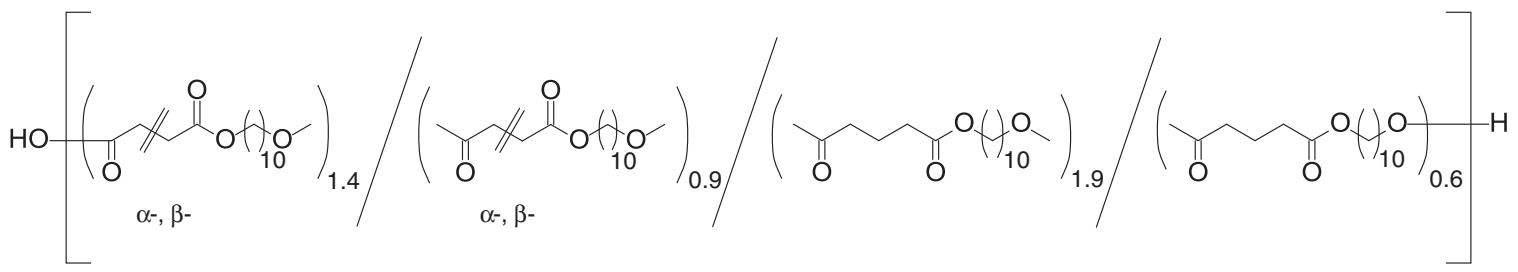

Scheme 6 Proposed structure for the polyester produced from itaconic anhydride (IAn), glutaric anhydride (GAn) and 1,10-decanediol (DD); (code 7). 
In the GAn reaction cases, OD seemed to be the most desirable among the four diols in terms of yield, molecular weight and numbers of unit per molecule, as observed previously. ${ }^{21}$ This may be due to the hydrophobicity of the reaction system, similar to the SAn reactions.

As $\mathrm{BD}$ was considered to be a bio-based material, the biomass contents of the products were 73 and $56 \mathrm{wt} \%$ (>25 wt\%); therefore, the polyesters can be considered biomass plastics (codes 1 and 2, Table 2).

\section{Crosslinking reaction}

The product polyesters have reactive vinylidene groups and are regarded as macromonomers when one vinylidene group is present in each molecule, and as telechelics or crosslinking agents when more than two vinylidene groups are in each molecule. In addition, the polyesters can be further modified via reaction of the vinylidene group(s). As an example of this polyester reactivity, a crosslinking reaction was attempted under radical conditions.

A powdered polyester sample (code 5, Table 2) was heated without solvent in air at $150{ }^{\circ} \mathrm{C}$ in a test tube. The sample seemed to begin gel formation after $3 \mathrm{~h}$, and gelation was complete after $27 \mathrm{~h}$, resulting in a hard polymer solid. The Fourier transform infrared spectroscopy spectrum of the starting polymer showed a strong absorption at $\sim 770 \mathrm{~cm}^{-1}$ owing to the vinylidene group (Figure $7 \mathrm{a}$ ). After $27 \mathrm{~h}$ at $150{ }^{\circ} \mathrm{C}$, the peak completely disappeared (Figure $7 \mathrm{~b}$ ), indicating that the vinylidene groups were involved in the crosslinking resulting in gelation. The results clearly suggest that the polymer is a reactive polyester.

As the product solid polyester is freely soluble in chloroform, the solid was dipped in chloroform and the mixture was stirred for $2 \mathrm{~h}$ at room temperature to extract soluble compounds. The mixture was filtered and the chloroform was evaporated. The extracted polymer amount corresponded to $5.0 \mathrm{wt} \%$ of the starting solid. The ${ }^{1} \mathrm{H}$ NMR spectrum of the extracted polymer showed a small number of vinylidene protons. These results suggest that the crosslinking reaction did not occur completely and/or that the ROACP product polyesters did not contain the IAn vinylidene double bond in all of the molecules, that is, the double bond was incorporated into a small number of the ROACP product molecules. If the latter is true, to

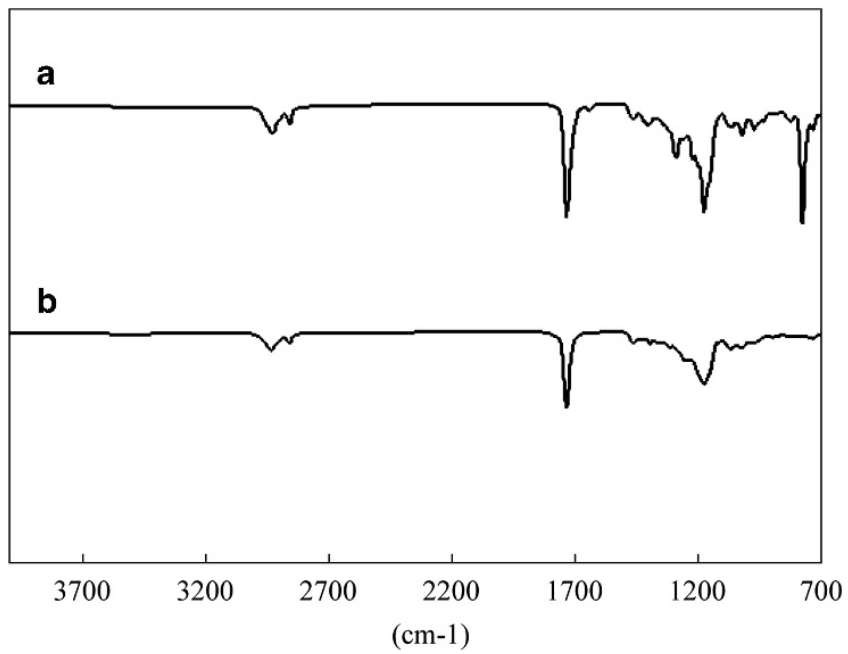

Figure 7 Fourier transform infrared spectroscopy (FT-IR) spectra of the polyester (code 5, Table 2) for crosslinking: (a) before the reaction and (b) after $27 \mathrm{~h}$ at $150^{\circ} \mathrm{C}$. obtain reactive polyesters with the double bond in at least one group in all of the polyester molecules, more detailed studies will be necessary, for example, further varying the feed molar ratio of the ROACP reactions.

\section{CONCLUSION}

IAn derived from renewable starting materials was used as a polymerization (ROACP) monomer with lipase catalysis to produce reactive polyesters possessing the vinylidene double bonds from IAn in good-to-high yields. The ROACP was performed via the monomer combination of IAn-SAn (or GAn)-diol, where BD, HD, OD or DD was employed as the diol monomer. The product polyesters had $M_{\mathrm{n}}$ values of 560-3690 and the double-bond content values were 1.2-3.1 per molecule. The product is a reactive polyester, as demonstrated by a crosslinking reaction. The product polyesters, therefore, have potential applications as macromonomers, telechelics or crosslinking agents. This study utilizes the renewable monomer IAn and the environmentally benign enzyme lipase as catalyst, thus providing a good example of green polymer chemistry.

1 Anastas, P. T. \& Warner, J. C. Green Chemistry: Theory and Practice (Oxford University Press, New York, NY, USA, 1998).

2 Coates, G. W. \& Hillmyer, M. A. Polymers from renewable resources. Macromolecules 42, 7987-7989 (2009).

3 Tsuji, H. \& Ikada, Y. Properties and morphology of poly(L-lactide) 4. effects of structural parameters on long-term hydrolysis of poly(L-lactide) in phosphate-buffered solution. Polym. Deg. Stab. 67, 179-189 (2000).

4 Fukushima, K., Furuhashi, Y., Sogo, K., Miura, S. \& Kimura, Y. Stereoblock poly(lactic acid): synthesis via solid-state polycondensation of a stereocomplexed mixture of poly(L-lactic acid) and poly(D-lactic acid). Macromol. Biosci. 5, 21-29 (2005).

5 Gupta, B., Revagade, N. \& Hilborn, J. Poly(lactic acid) fiber: an overview. Prog. Polym Sci. 32, 455-482 (2007)

6 Fukushima, K., Chang, Y. -H. \& Kimura, Y. Enhanced stereocomplex formation of poly(L-lactic acid) and poly(D-lactic acid) in the presence of stereoblock poly(lactic acid). Macromol. Biosci. 7, 829-835 (2007).

7 Jiang, X., Smith, M. R. III \& Baker, G. L. Water soluble thermoresponsive polylactides. Macromolecules 41, 318-324 (2008).

8 Chuma, A., Hom, H. W., Swope, W. C., Pratt, R. C., Zhang, L., Lohmeijer, B. G. G., Wade, C. G., Waymouth, R. M., Hedrick, J. L. \& Rice, J. E. The reaction mechanism for the organocatalytic ring-opening polymerization of L-lactide using a guanidine-based catalyst: hydrogen-bonded or covalently bound? J. Am. Chem. Soc. 130, 6749-6754 (2008)

9 Jing, F. \& Hillmyer, M. A. A bifunctional monomer derived from lactide for toughening polylactide. J. Am. Chem. Soc. 130, 13826-13827 (2008)

10 Pitet, L. M., Amendt, M. A. \& Hillmyer, M. A. Nanoporous linear polyethylene from a block polymer precursor. J. Am. Chem. Soc. 132, 8230-8231 (2010).

11 Nishida, H., Andou, Y., Watanabe, K., Arazoe, Y. Ide, S. \& Shirai, Y. Poly(tetramethy glycolide) from renewable carbon, a racemization-free and controlled depolymerizable polyesters. Macromolecules 44, 12-13 (2011).

12 Stoclet, G., Seguela, R., Lefebvre, J. M., Li, S. \& Vert, M. Thermal and strain-induced chain ordering in lactic acid stereocopolymers: influence of the composition in stereomers. Macromolecules 44, 4961-4969 (2011).

13 Shin, E. J., Jones, A. E. \& Waymouth, R. M. Stereocomplexation in cyclic and linear polylactide blends. Macromolecules 45, 595-598 (2012).

14 Ishimoto, K., Arimoto, M., Ohara, H., Kobayashi, S., Ishii, M., Morita, K., Yamashita, H. \& Yabuuchi, N. Biobased polymer system: miniemulsion of poly(alkyl methacrylate-graft-lactic acid)s. Biomacromolecules 10, 2719-2723 (2009).

15 Okuda, T., Ishimoto, K., Ohara, H. \& Kobayashi, S. Renewable biobased polymeric materials: facile synthesis of itaconic anhydride-based copolymers with poly(L-lactic acid) grafts. Macromolecules 45, 4166-4174 (2012)

16 Ishimoto, K., Arimoto, M., Okuda, T., Yamaguchi, S., Aso, Y., Ohara, H., Kobayashi, S., Ishii, M., Morita, K., Yamashita, H. \& Yabuuchi, N. Biobased polymers: synthesis of graft copolymers and comb polymers using lactic acid macromonomer and properties of the product polymers. Biomacromolecules 12, 3757-3768 (2012).

17 Kobayashi, S. Enzymatic polymerization: a new method of polymer synthesis. J. Polym. Sci. Part A 37, 3041-3056 (1999).

18 Kobayashi, S., Uyama, H. \& Kimura, S. Enzymatic polymerization. Chem. Rev. 101, 3793-3818 (2001)

19 Kobayashi, S. Recent developments in lipase-catalyzed synthesis of polyesters Macromol. Rapid Commun. 30, 237-266 (2009).

20 Kobayashi, S. \& Makino, A. Enzymatic polymer synthesis: an opportunity for green polymer chemistry. Chem. Rev. 109, 5288-5353 (2009). 
21 Kobayashi, S. \& Uyama, H. Enzymatic polymerization of cyclic anhydrides and glycols by a lipase catalyst. Macromol. Chem. Rapid Commun. 14, 841-844 (1993).

22 Matsumura, S., Okamoto, T., Tsukada, K. \& Toshima, K. Novel lipase-catalyzed ringopening copolymerization of oxiranes and succinic anhydride forming polyesters bearing functional groups. Macromol. Rapid Commun. 19, 295-298 (1998).

23 Soeda, Y., Okamoto, T., Toshima, K. \& Matsumura, S. Enzymatic ring-opening polymerization of oxiranes and dicarboxylic anhydrides. Macromol. Biosci. 2, 429-436 (2002).

24 Rajkhowa, R., Varma, I. K., Albertsson, A.-C. \& Edlund, U. Enzyme-catalyzed copolymerization of oxiranes with dicarboxylic acid anhydrides. J. Appl. Polym. Sci. 97, 697-704 (2005).

25 Kobayashi, S., Uyama, H., Suda, S. \& Namekawa, S. Dehydration polymerization in aqueous medium catalyzed by lipase. Chem. Lett. 105 (1997).

26 Suda, S., Uyama, H. \& Kobayashi, S. Dehydration polycondensation in water for synthesis of polyesters by lipase catalyst. Proc. Jpn Acad. B. 75, 201-206 (1999).

27 Manabe, K., Sun, X. -M. \& Kobayashi, S. Dehydration reactions in water. Surfactanttype Brønsted acid-catalyzed direct esterification of carboxylic acids with alcohols in an emulsion system. J. Am. Chem. Soc. 123, 10101-10102 (2001).

28 Manabe, K., Imura, S., Sun, X. -M. \& Kobayashi, S. Dehydration reactions in water. Brønsted acid-surfactant-combined catalyst for ester, ether, thioether, and dithioacetal formation in water. J. Am. Chem. Soc. 124, 11971-11978 (2002).

29 Taden, A., Antonietti, M. \& Landfester, K. Enzymatic polymerization towards biodegradable polyester nanoparticles. Macromol. Rapid Commun. 24, 512-516 (2003).
30 de Barrons, D. P. C., Fonseca, L. P., Cabral, J. M. S., Aschenbrenner, E. M., Weiss, C. K. \& Landfester, K. Miniemulsion as efficient system for enzymatic synthesis of acid alkyl esters. Biotech. Bioeng. 106, 507-515 (2010).

31 Ohara, H., Onogi, A., Yamamoto, M. \& Kobayashi, S. Lipase-catalyzed oligomerization and hydrolysis of alkyl lactates: direct evidence in the catalysis mechanism that enantioselection is governed by a deacylating step. Biomacromolecules 11, 2008-2015 (2010).

32 Ohara, H., Nishioka, E., Yamaguchi, S., Kawai, F. \& Kobayashi, S. Protease-catalyzed oligomerization and hydrolysis of alkyl lactates involving L-enantioselective deacylating step. Biomacromolecules 12, 3833-3837 (2011).

33 Werpy, T. \& Petersen, G. Top Value Added Chemicals from Biomass (The National Renewable Energy Labolatory \& DOE National Labolatory, Washington, DC, USA, 2004).

34 Puskas, J. E., Sen, M. Y. \& Seo, K. S. Green polymer chemistry using nature's catalyst, enzymes. J. Polym. Sci. Part A 47, 2959-2976 (2009).

35 Kobayashi, S. Lipase-catalyzed polyester synthesis: green polymer chemistry. Proc. Jpn Acad. B 86, 338-365 (2010).

36 Kobayashi, S., Ritter, H. \& Kaplan, D. Enzyme-catalyzed synthesis of polymers. Adv. Polym. Sci. 194, 1-224 (2007).

37 Palmans, A. R. A. \& Heise, A. Enzymatic polymerization. Adv. Polym. Sci. 237, 1-143 (2010).

38 Ferraboschi, P., Casati, S., Grisenti, P. \& Santaniello, E. Selective enzymatic transformation of itaconic acid derivatives: an access to potentially useful building blocks. Tetrahedron 50, 3251-3258 (1994).

Supplementary Information accompanies the paper on Polymer Journal website (http://www.nature.com/pj) 